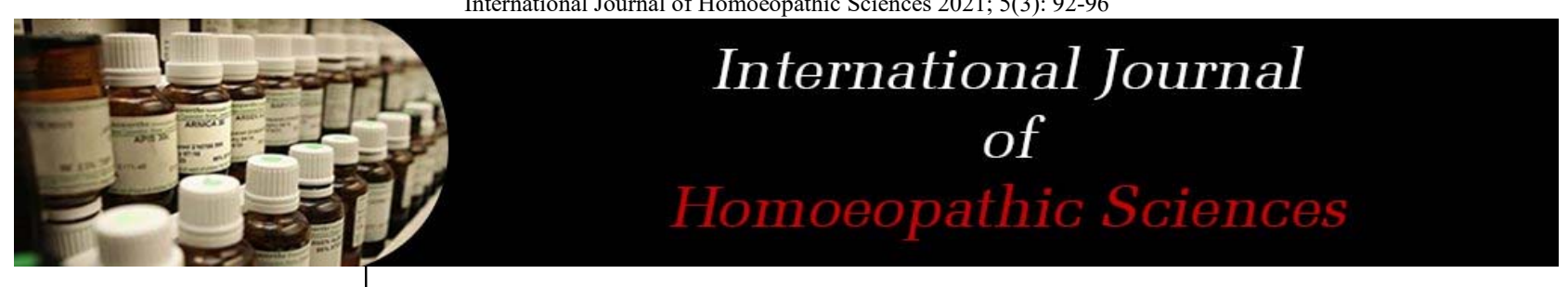

E-ISSN: 2616-4493 P-ISSN: 2616-4485 www.homoeopathicjournal.com IJHS 2021; 5(3): $92-96$ Received: 25-05-2021 Accepted: 27-06-2021

Dr. Dhanya G Nair BHMS, MD (Hom.), Dr. Dhanya's Homoeopathic Multispeciality Clinic Thottakad, Kottayam, Kerala, India

Corresponding Author: Dr. Dhanya G Nair BHMS, MD (Hom.), Dr. Dhanya's Homoeopathic Multispeciality Clinic Thottakad, Kottayam, Kerala, India

\section{Effectiveness of homoeopathic treatment in managing acute cystitis in females of adolescent age group}

\author{
Dr. Dhanya G Nair
}

DOI: https://doi.org/10.33545/26164485.2021.v5.i3b.412

\begin{abstract}
Due to their structural peculiarity, girls are prone to develop urinary infections. Lower urinary infections, if not treated promptly can lead to the ascent of the infection to kidneys leading to pyelonephritis. Sepsis is another complication. Repeated use of antibiotics may affect the intestinal micro flora. This study aims at understanding the effectiveness of Homoeopathic constitutional remedy in managing acute cystitis in adolescent females by minimizing or preventing recurrent attacks and complications. The objectives of the study are, to study the improvement of the patient based on symptom relief and reduced pus cell count in urine and to study about the clinical presentation of acute cystitis in adolescent girls.
\end{abstract}

Keywords: adolescence, cystitis, recurrence, complications, homoeopathy, improvement

\section{Introduction}

Urinary tract infection is a common problem in developing countries like India . About $20 \%$ of women have a UTI at some time in their life ${ }^{[1]}$. Bacterial bladder infections may occur in younger females as a result of lack of hygiene. Vaginal infections resulting from poor personal hygiene is one of the reasons for urinary infections. In women, the ascent of organisms into the bladder is easier than in men due to their shorter urethra and its proximity to the anus. Immediately after puberty, the incidence of urinary infection in girls rises to about $10 \%$. Of the lower urinary tract infections, cystitis is the most common one.

Urinary infections are more prevalent in the girls of the rural community as well as girls belonging to poor socio-economic group. The reason for this is that they lack proper facilities at school and home for maintaining personal hygiene. Lack of hygienic toilet facilities at school may prevent the girls from attending to the nature's call in time. Lack of hygiene during menstrual periods is another reason for cystitis. Wearing tight fitting clothes is yet another reason.

Complications of the urinary tract like renal calculi, vescicoureteric reflux and systemic diseases like Diabetes mellitus are also reasons for urinary tract infections. Hospital acquired infections are also not infrequent ${ }^{[3]}$

The World Health Organization defines an adolescent as any person between ages 10 and 19 [2].

Among adolescent girls, the most frequent causes of lower urinary tract infections are poor hygiene, especially personal hygiene, decreased water intake and holding urine for long. As far as personal hygiene is concerned, many girls are unaware of the need for keeping them clean. Washing the genital area after urination is not followed by many girls. The genital area should be wiped from front to back after washing. This is not done by many girls. These two factors contribute much to the development of urinary tract infections. In rural areas, where there is scarcity of pure water supply, the personal needs of the female community are not satisfied. Using homemade sanitary pads during menstrual periods unhygienically can cause urinary infections. It is the need of the time that the essential needs of the village community have to be given more importance by the government.

Many girls have now developed the habit of not drinking enough water. In a tropical country like India, at least 2 litres of water is essential for bodily needs. The next major cause is holding urine for long due to various reasons. 


\section{Materials and Methods}

\section{Sources of Data}

A sample of 30 cases of acute cystitis patients attending the Out Patient Department and In Patient Department of Sarada Krishna Homoeopathic Medical College Hospital were considered for the study, from the time period of Dec.2015 to April 2017.

\section{Method of Collection of Data}

Sample Size - 30 diagnosed cases of acute cystitis.

Sampling Techniques - Deliberate sampling. It is the term given to non-probability sampling, where cases are selected based on the inclusion and exclusion criteria, from the patients attending OPD at a given phase of time.

\section{Study Design}

- The data was collected by deliberate sampling technique as per the inclusion criteria and processed in a standardized case record. The case is analysed accordingly and totality was evolved. Medicines were prescribed on the totality of a particular case.

- The potency selection and repetition of the dose were done according to the demand of the case. Follow up in each case was planned for every two hours.

- During the follow up, each case was evaluated according to the scoring criteria, which included the intensity of the symptoms before and after treatment and time taken for cure.

\section{Inclusion Criteria}

- Females in the age group of 10-19 years.

- Patients with the clinical presentation of cystitis.

- Cases which fulfil the diagnostic criteria.

\section{Exclusion Criteria}

- Females below 10 years and above 19 years.

- Pregnant patients.

- Patients with Diabetes mellitus.

- Patients with complications of the urinary tract.

- Patients using other modes of treatment.

\section{Assessment of Effectiveness}

Effectiveness of the treatment was assessed on the basis of the decrease in the symptom severity or disappearance of the symptoms and a reduction in the number of pus cells in urine.

\section{Observations and Results}

A sample of thirty cases from the patients who attended the OPD and IPD of Sarada Krishna Homoeopathic Medical College and Hospital were taken for this study. The indicated medicine was administered. All the thirty cases were followed up every 2 hours and were subjected to statistical study. The results are presented on the basis of data obtained from study group. The following charts reveal the observations and results of this study:

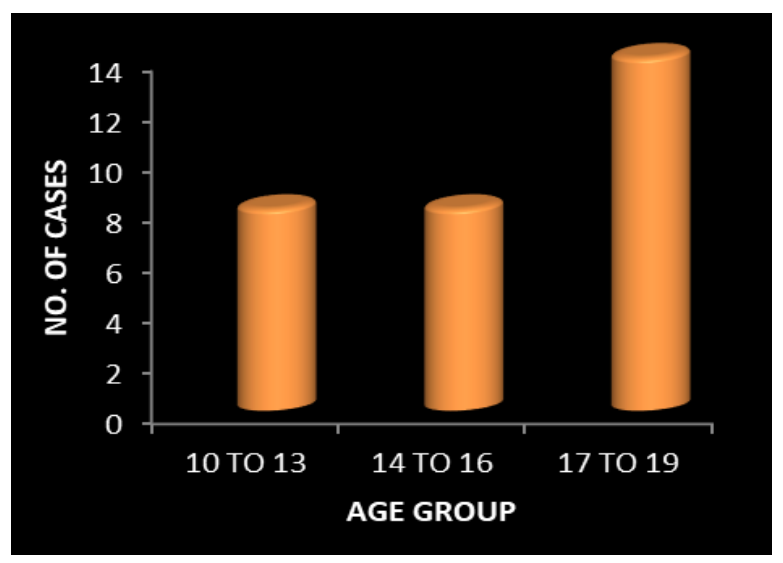

Fig 1: Distribution of Cases According to Age

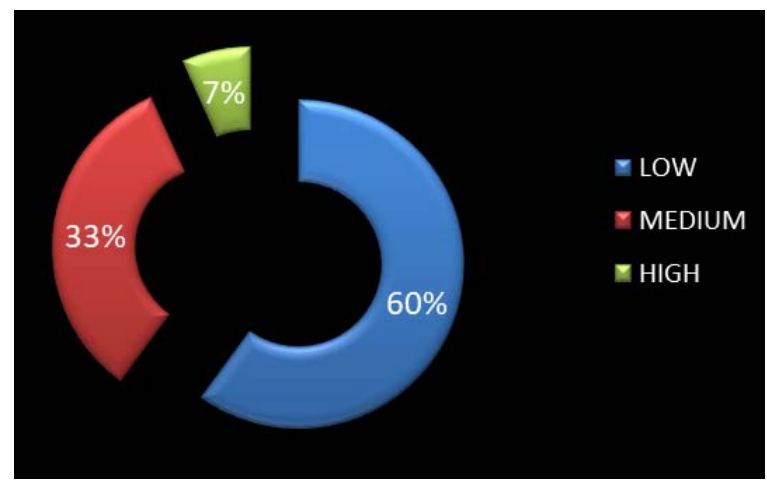

Fig 2: Distribution of Cases According To The Socio-Economic Status

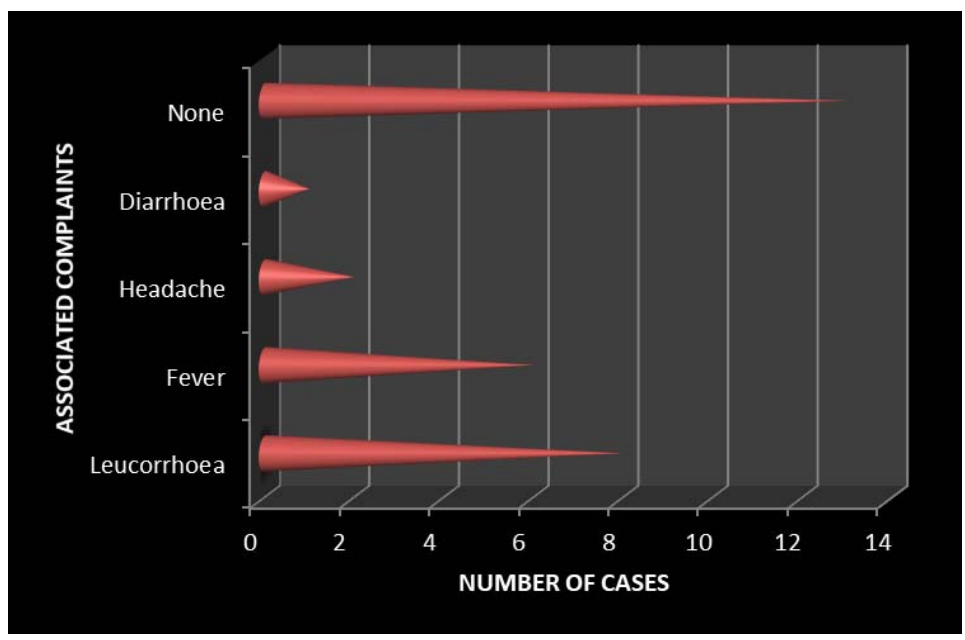

Fig 3: Distribution of Cases According to The Associated Complaints 


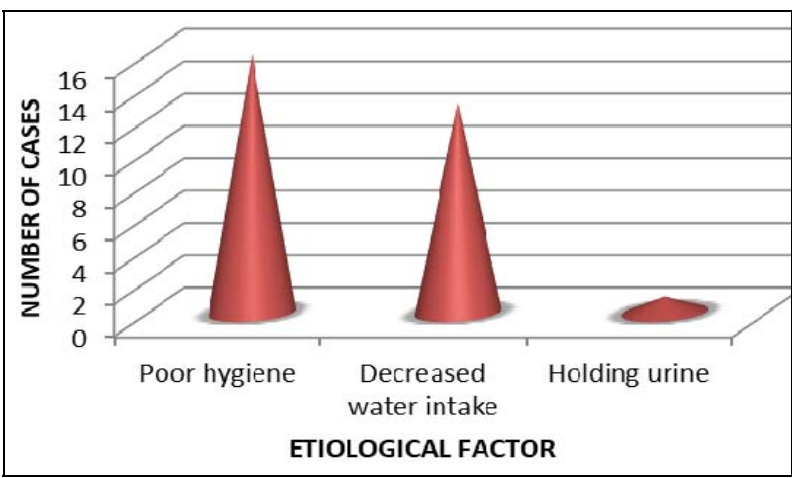

Fig 4: Distribution of Cases According to The Etiological Factor

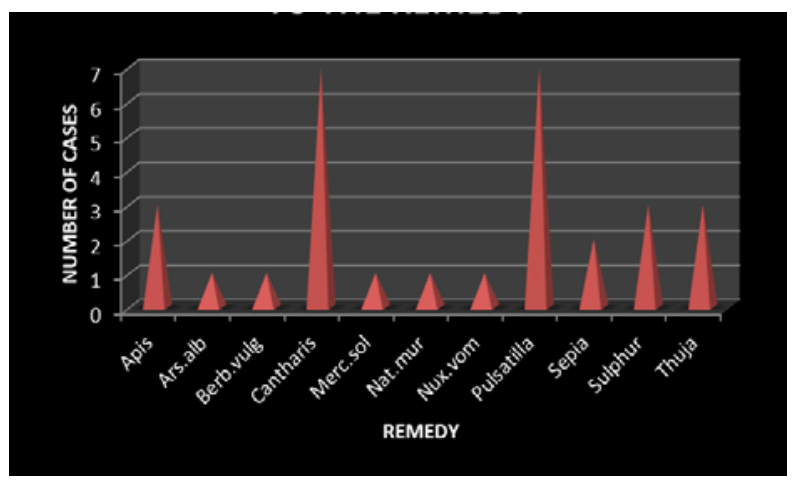

Fig 5: Distribution of Cases According to The Remedy

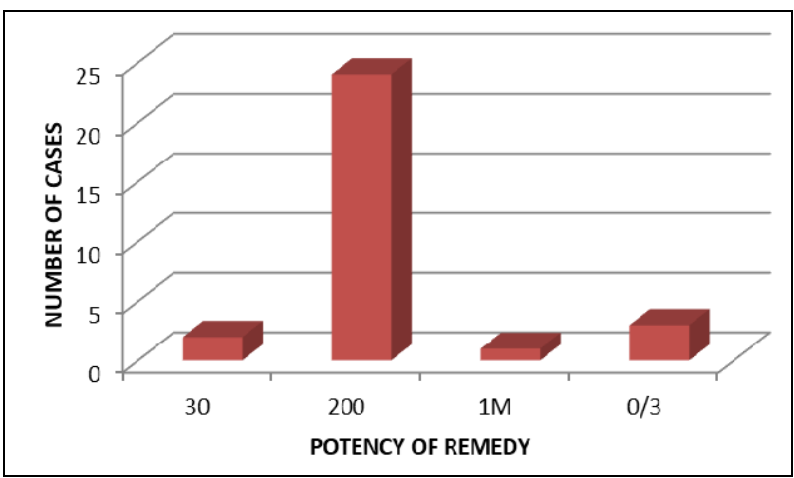

Fig 6: Distribution of Cases According to The Potency Used

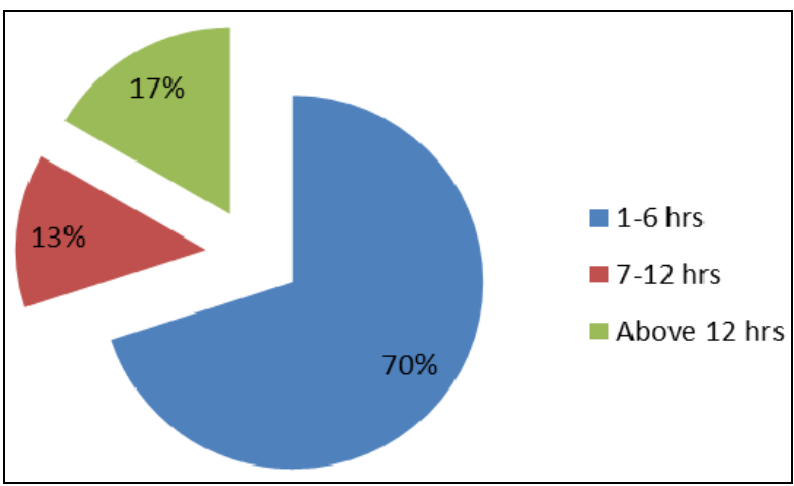

Fig 7: Distribution of Cases According To The Time Of Response

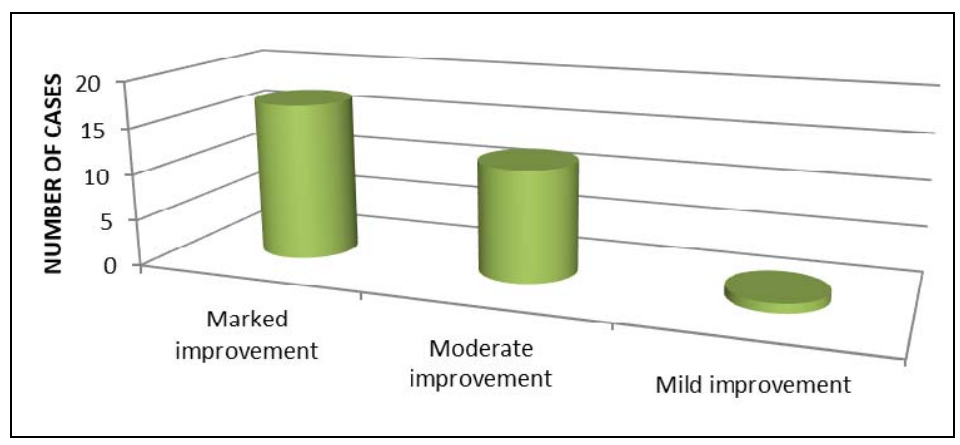

Fig 8: Distribution of Cases According to The Improvement Status

\section{Discussion}

For clinical assessment, before and after treatment symptom score were considered from the details during initial visit and later after treatment period got over, then paired ' $t$ ' test was applied for comparing the symptoms before and after treatment. The study was validated based on the findings and compared with the reliable literature and updates from text books and Journals.

Age: Out of the 30 cases, patients belonging to the age group $10-13$ were $8(26.66 \%)$, patients belonging to the age group 14-16 were $8(26.66 \%)$ and those belonging to $17-19$ were $14(46.66 \%)$. This shows that as age increases, the tendency to be affected by cystitis also increases. Literature shows that about $1 \%$ of school girls (aged 5 to 14 years) have bacteriuria and this figure increases to about $4 \%$ by young adulthood and that by an additional $1 \%$ to $2 \%$ per decade of age ${ }^{[4]}$.

Area of Dwelling: Out of the 30 cases, 18 cases (60\%) belonged to the rural community whereas 12 cases $(40 \%)$ belonged to the urban community.

It indicates that due to the proximity of rural areas to SKHMC hospital, majority of my cases were from rural area.

Socio-Economic Status: Out of the 30 cases, 18 patients $(60 \%)$ were from lower socio-economic group, 10 patients $(33.33 \%)$ were of medium socio-economic status and 2 patients $(6.66 \%)$ were of higher socio-economic status. It shows that girls of lower socio-economic status are more affected by acute cystitis due to the lack of hygiene. Vaginal infections resulting from poor personal hygiene can be a cause for urinary infections ${ }^{[5]}$.

Associated Complaints: Out of the 30 cases, 8 patients $(26.66 \%)$ had the associated complaint of leucorrhoea, 6 patients $(20 \%)$ had fever,2 patients $(6.66 \%)$ had headache, 1patient $(3.33 \%)$ had diarrhoea and 13 patients $(43.33 \%)$ had no associated complaints. Literature says that lower 
urinary tract infections like cystitis usually produce no constitutional symptoms or fever. If at all present, they disappear within hours with proper treatment ${ }^{[6]}$. Majority of the girls had leucorrhoea. Leucorrhoea can occur due to vaginal infections as a result of poor hygiene ${ }^{[5]}$. So both cystitis and leucorrhoea occur as a result of poor personal hygiene. And also UTI can be a reason for leucorrhoea ${ }^{[2]}$. Diarrhoea was present in one case. In diarrhoea, there is an increased chance for contamination of the female urinary tract with intestinal bacteria ${ }^{[7]}$. It can be a reason for cystitis. If headache is present in urinary tract infection along with the classical triad of pyelonephritis, i.e fever, loin pain and tenderness over the kidneys, we can suspect pyelonephritis ${ }^{[8]}$.

Etiological Factors: Out of the 30 cases, the etiological factor was poor hygiene in 16 patients $(53.33 \%)$, reduced water intake was the etiological factor in 13 patients $(43.33 \%)$ whereas 1 patient $(3.33 \%)$ had the etiological factor of holding urine ${ }^{[13]}$. Poor hygiene was found to be the most common causative factor ${ }^{[5]}$.

Remedy: Out of the 30 cases, 3 patients (10\%) were treated by Apis. mel, 1 patient (3.33\%) was treated by Ars.alb, 1 patient $(3.33 \%)$ by Berb.vulg, 7 patients $(23.33 \%)$ by Cantharis, 1 patient (3.33\%) was given Merc. sol, 1 case $(3.33 \%)$ was treated by Natrum. mur, Nux. vom was given to 1 patient $(3.33 \%)$, Pulsatilla was given to 7 patients $(23.33 \%)$, Sepia was given to 3 patients $(6.66 \%)$, Sulphur and Thuja covered 3 cases each (10\%) Cantharis, the renowned remedy for urinary infections, along with Pulsatilla were proved to be most useful in treating acute cystitis. Almost all the symptoms of cystitis have been covered by Cantharis. In earlier studies on cystitis, Cantharis was proved to be one of the remedies effective in managing cystitis [10]. Most of the patients gave the symptoms of cutting pain before, during and after micturition, there was a constant desire to micturate and the urine passed out in drops. All these symptoms are covered by Cantharis. Like that, the patients who were given Pulsatilla had the symptoms of pain in the bladder after micturating and involuntary micturition at night. They also had chilliness.

Potency of the Remedy: Out of the 30 cases, 2(6.66\%) cases were given $30^{\text {th }}$ potency of the remedy, 24 cases $(80 \%)$ were given $200^{\text {th }}$ potency, $1 \mathrm{M}$ was given to 1 patient $(3.33 \%)$ whereas 3 patients $(10 \%)$ were given the selected remedy in $0 / 3$ potency. So $200^{\text {th }}$ potency was found to be the most recommended potency in cases with acute cystitis.

Time of Response: Time of response is the time taken by the medicine to show action and patients to feel better. Out of the 30 cases, 21 cases $(70 \%)$ started responding to the treatment within 1-6 hours, 14 patients $(13.33 \%)$ responded within 7-12 hours whereas more than 12 hours were needed for 5 patients $(16.66 \%)$ for responding to the treatment. Shorter the time duration of action of remedy, the care given to the patient is graded as marked, moderate and mild improvement and thus patient satisfaction is also guaranteed.

Improvement Status: Out of the 30 cases treated, 17 cases (56.6\%) showed marked improvement, 12 cases (40\%) showed moderate improvement and 1 patient (3.33\%) showed mild improvement with the treatment. So majority of the cases showed marked improvement from the Homoeopathic treatment.

Results obtained from the study were processed for reliability test through paired ' $t$ ' test. On referring to the paired ' $t$ ' test with $n-1$ degree of freedom, the value of ' $t$ ' for probability of 0.05 is 2.048 . Since the calculated value of ' $t$ ' (14.69) is greater than the tabled value of ' $t$ ' (2.048), I conclude that the null hypothesis is rejected and the result is significant and this study shows significant reduction in the disease intensity scores after giving homoeopathic medicines. Therefore, Homoeopathic medicines are effective in managing acute cystitis in adolescent girls.

\section{Conclusion}

- Majority of patients with acute cystitis belong to age group 17-19 years.

- Acute cystitis has more preponderance to occur in rural areas.

- Acute cystitis is more prevalent in the lower socioeconomic group.

- The etiological factors significantly observed in the cases are poor hygiene, decreased water intake and holding urine.

- The common complaints associated with cystitis are fever, headache diarrhoea and leucorrhoea. Majority of the cases had no associated complaints.

- The time taken for response to the treatment was within 1-6 hours in majority of the cases.

- The medicines which are found to be most effective include Cantharis and Pulsatilla.

- Most commonly used effective potency is 200 .

- Majority of the cases showed marked improvement from the treatment.

\section{Acknowledgement}

With a grateful heart I thank Almighty God whose grace strengthens me to complete this work with maximum involvement.

I express my sincere thanks to my guide Dr. T.AJAYAN, M.D. (Hom.), Head of Department of Practice of Medicine, Sarada Krishna Homoeopathic Medical College, Kulasekharam, for his valuable ideas, guidance and encouragement given throughout the period of study.

I would like to extend my thanks to my teacher Dr. C.V. Chandraja Rathish for her timely support and encouragement. It is my duty to express my sincere thanks to all my teachers who lit the lamp of knowledge in me.

I express my love and gratitude towards my beloved parents Mr. S. P. Gopalakrishnan Nair and S Lathika Devi for their support and encouragement throughout my life. I also extend my sincere thanks to the patients who participated in the study.

\section{References}

1. Das KV. Krishna. Urinary tract infection. Text book of Medicine. $5^{\text {th }}$ ed.Ch.172.New Delhi. Jaypee Brothers Medical publishers (p) Ltd. 2008, 1135.

2. CsikszentmihalyiMihalyi.https://www.britannica.com/s cience/adolescence.

3. Stamm Walter E. Urinary tract infections, Pyelonephritis and Prostatitis. Levy Harrisons Principles of Internal Medicine. 15 ${ }^{\text {th }}$ ed.Vol 2. USA. Mc. 
Graw Hill Medical publishing division. 2001, 1620.

4. Walsh Patrik C. Urinary tract infection. Campbell's urology. $7^{\text {th }}$ ed. W B Saunder's Company 1998;1:131, $537,588,589$.

5. Dr. Vaishnav Shweta. https://drshwetavaishnav.wordpress.com/2011/04/28/le ucorrhoea.

6. Klegman, Stanton ST. Geme, Schor, Behrman. Urinary tract infections. Nelson Textbook of Pediatrics.19 ed.Vol.2 Philadelphia. Elsevier Saunders 2013, 1830.

7. Kumar Praveen, Clark Michael. Urinary tract infections. Kumar and Clark Clinical Medicine. $6^{\text {th }}$ ed. London. Elsevier Saunders 2005, 637, 638, 639, 640.

8. Pabubidri, Daftary N Shirish. Diseases of the urinary system. Shaw's textbook of gynaecology. $14^{\text {th }}$ ed.Ch.15 New Delhi. Elsevier India Pvt Ltd.2008;160:15.

9. Feminine Health. Encyclopedia of health. $4^{\text {th }}$ ed. Rosen Publishing group.

10. Efficacy of Homoeopathy in the management of cystitis-Dr. Preema Niyas.www.similima.com 